\title{
Oil Spill Influence on Vegetation in Nigeria and Its Determinants
}

\author{
Bahaa Mohamadi, Fujiang Liu*, Zhong Xie \\ Faculty of Information Engineering, China University of Geosciences, Wuhan 430074, P.R. China
}

Received: 14 April 2016

Accepted: 12 June 2016

\begin{abstract}
Nigeria is facing some serious environmental challenges due to frequent oil spills, especially in the Niger Delta. Oil spills are one of the main sources of environmental contamination in the country. Daily oil spill incidents have polluted the air, soil, natural vegetation, farmlands, sources of drinking water, and fishing creeks. Multi endmember spectral mixture analysis (MESMA) was used to calculate vegetation percentage inside each pixel of Landsat7 images before and after oil spill incidents to evaluate the negative influence of spilled oil on impacted areas' vegetation. 163 recorded oil spill incidents between 2011 and 2012 were investigated in the Rivers State, Nigeria for this purpose. Results revealed that $73 \%$ of studied spill-impacted areas have vegetation losses caused by oil spills. Recorded oil spill data were used to create a comprehensive spatial database using GIS to examine which types of data could be potential determinants for oil spill influence on Nigeria's vegetation. Among fifteen different types of examined oil spill data; this study concluded that impacted area size, spilled oil volume, residual oil volume on site, impacted area environment, and response, recovery, and cleanup timing are major determinants for oil spill influence on the Niger Delta's vegetation.
\end{abstract}

Keywords: GIS, Nigeria, oil spill, remote sensing, vegetation

\section{Introduction}

Petroleum industry activities in Nigeria are largely responsible for environmental degradation in oil production areas [1]. The main oil production region in Nigeria is the Niger Delta in the southern part of the country, which possess the continent's biggest oil reserves [2].

An oil spill is described as a release of liquid hydrocarbons into the environment as a result of human activities [3]. It is considered as one of the biggest problems caused by petroleum industry in Nigeria. Frequent oil leakages from different oil facilities have

*e-mail: 305617765@qq.com polluted the air, soil, drinking water, and fishing creeks. It has destroyed many mangrove swamps and farmlands in the region. This has led to serious economic losses to local inhabitants, who depend mostly on fishing and subsistence farming for their livelihoods [4-6]. Oil spills in the region are one of the main reasons for selecting the Niger Delta as one of the most polluted places in the world in 2013 [2].

Despite the known fact that not all oil spills in Nigeria are reported [7], the Nigerian National Petroleum Corporation (NNPC) has reported more than 20,000 oil spill incidents in the transportation pipeline sector only between 2006 and 2013 [8]. In addition, an independent assessment estimated that more than 115,000 barrels of oil are spilled into the Niger Delta environment every year [7]. 
Oil pipeline vandalism by indigenous inhabitants is a major source of oil spills in Nigeria and poses several serious economic and environmental problems. 2014's (NNPC) annual bulletin reported that vandalism is the cause of more than $98 \%$ of pipeline breaks during 2013 in Nigeria [8].

Recently, the availability of low-cost aerospace remote sensors with wide and repetitive coverage gives remote sensing an advantage in detecting and monitoring environmental changes across the globe [9]. Remote sensors have the capability of detecting hydrocarbon spillage on various kinds of surfaces, and multi-temporal remote sensing images can provide essential information required for detecting environmental changes caused by oil spills [10].

Studies of near-shore and on-land spills detection using remote sensing techniques are very rare compared to that of offshore spills [11]. However, there is an increase and considerable interest in the study of plant stress caused by crude oil spillage using these techniques in the last few years [12].

Geographic information system (GIS) provides an efficient storage, retrieval, visualization, and analysis interface of geographic data combined with environmental and industrial information [13]. Using GIS can improve the efficiency of oil spill emergency planning and help speed up the decision-making process [14].

Many researchers have used remote sensing and GIS to examine the environmental impact of marine oil spills (e.g., Banks [15], Teruhisa et al. [16], and Roberts et al. [17]). Among many studies, MESMA was used to detect the environmental impact of Deep Water Horizon in Mishra et al. [18], Arslan et al. [19], Kokaly et al. [20], and Peterson et al. [21]. However, on-land oil spill studies are few compared to those in marine oil spill studies (e.g., Saif ud din et al. [22], and Hese and Schmullius [23]).

The Niger Delta is the third largest mangrove wetland in the world, and the biggest river delta in Africa [2]. The total area of the Niger Delta is approximately $112,000 \mathrm{~km}^{2}$ [27], it has a tropical climate, and receives between 2,400 and 4,200 $\mathrm{mm}$ of precipitation annually, mainly during the rainy seasons between April and November, with high temperature and humidity levels [2, 28-29]. Flora and fauna in the delta are very diverse. However, the main vegetation type in the Niger Delta is mangrove forests, which occupy an area between 5,000 and 8,600 $\mathrm{km}^{2}$ [2]. Different vegetation types are also represented, including large freshwater swamp plants and Napa Palms [30-31].

Because of the high amount of oil spills in the Niger Delta, many researchers have used GIS and remote sensing to study different aspects of this problem. For example, Anifowose et al. [24] has focused attention on spills caused by pipeline attacks in the Niger Delta, and connected these incidents to the socio-economic situation in spill incidents areas. Orimoogunje and Ajibola-James [6] has estimated the recovery progress of affected mangroves by spilled oil in the Niger Delta using satellite images. Adamu et al. [25], has analyzed the spectral reflectance of contaminated

a)

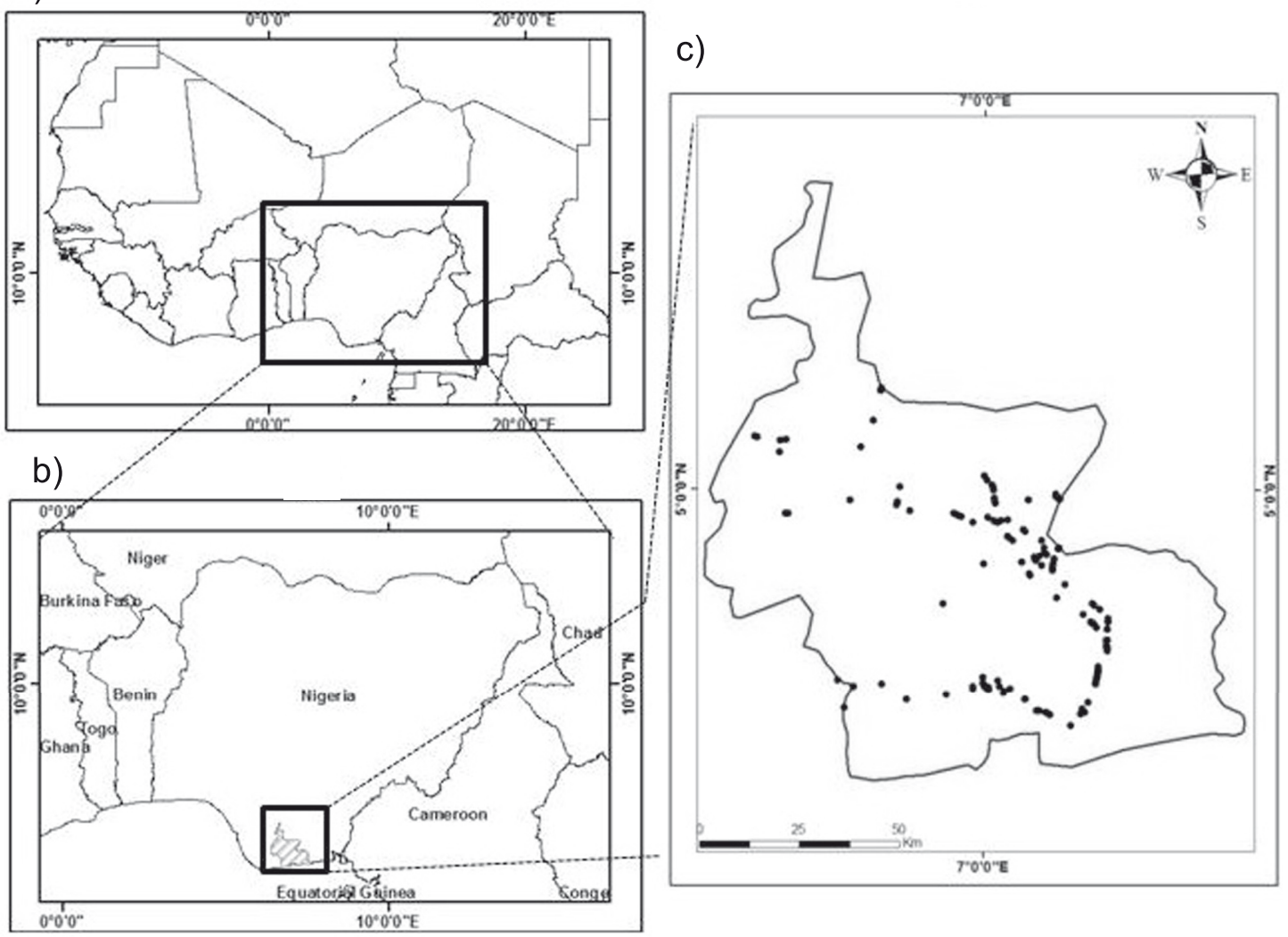

Fig. 1. Study area: a) Nigeria's location in West Africa, b) Rivers State location in Nigeria, c) the study's selected oil spill sites. 
mangrove and swamp vegetation areas, then compared between vegetation spectra of polluted and non-polluted sites on Landsat images. Anifowose et al. [26], has studied the spatial relationship between waterways and downstream pipelines to identify points on pipeline river crossings that are sensitive to oil spills.

Rivers State is located in the southern part of the Niger Delta (Fig. 1) with an area of approximately $10,400 \mathrm{~km}^{2}$, and high population projection of more than 6.5 million inhabitants in 2015 [27]. It is bordered by Akwa Ibom State in the east; Delta and Bayelsa states to the west; Anambra, Imo, and Abia states to the north; and the Atlantic Ocean in to the south [32]. Rivers State was selected for our study due to its importance in the Nigerian oil sector, and more importantly it had more than $50 \%$ of oil spill incidents recorded by Shell Petroleum Development Company (SPDC) among all nine states of the Niger Delta during the study period in 2011 and 2012 [33].

This study attempts to gain a comprehensive insight into the severity of oil spills on Nigeria's vegetation by evaluating the vegetation loss caused by oil spills in Nigeria's Rivers State during 2011 and 2012. MESMA results were used to compare vegetation percentages inside each Landsat7 pixel within 163 spill-impacted areas, and defined different determinants that increase the influence of oil spills on Delta vegetation.

\section{Materials and Methods}

\section{Data Acquisition}

Data have been collected from two distinct sources: first is the joint investigation reports of oil spills in the Niger Delta [33], which was reported by SPDC for 2011 and 2012. There were 201 on-land oil spill incidents occurring in Rivers State during this period. 163 oil spill impacted areas were selected to detect vegetation loss inside their impacted areas. These 163 incidents were selected due to the spilled oil volume (more than one barrel) and impacted area size (more than $10 \mathrm{~m}^{2}$ ). These reports were used to build a comprehensive spatial database of oil spills data for spatial analysis purposes.

The second data source is Landsat Enhanced Thematic Mapper Plus (Landsat ETM+) images [34]. These images were used to remotely detect vegetation loss inside oil spill impacted areas during the study period. Two images were selected for each path/row to cover analysis result gaps caused by the high density of clouds in this tropical area from one side, and cover Landsat7 strips gaps caused by the scan line corrector (SLC) failure of Landsat7 since 31 May 2003 [35] from the other side.

Examined images were selected during the dry season of the study area for two reasons: 1) to avoid large water bodies caused by the high water levels in streams and swamps during the wet season and 2) to avoid the annual precipitation changes that could influence the investigated vegetation's phonology. Images were chosen within narrow time periods for the same purpose. The selected images were collected during three distinct time periods: 4-29 December 2010, 7 December 2011 to 17 January 2012, and 25 December 2012 to 19 January 2013.

\section{Data Preparation}

We used ENVI and ARCGIS software for data preparation and analysis. Two feature class layers were created using SPDC oil spill report data for Rivers State during the study period. The first layer is a point feature class to represent oil spill sites, and the second layer is a polygon feature class to represent oil spill impacted areas. Absolute $\mathrm{x}, \mathrm{y}$ tool was used to digitize oil spill sites and impacted areas in the ARCGIS environment.

Landsat7 images that used in this research are L1T data which has been radiometrically, geometrically, and terrain corrected [36-38]. Hence, only fast line-of-sight atmospheric analysis of hypercubes (FLAASH) was applied to atmospherically correct all Landsat7 satellite images.

\section{Vegetation Loss Detection}

MESMA is producing by using VIPER Tools add-on in ENVI software environment. It is an extension of simple spectral mixture analysis (SMA). MESMA is a sub-pixel analysis method that can detect quantities of a target that is much smaller than the pixel size. It has the ability to test multi-spectral signatures for the same endmember inside each pixel, and select the best-fitting one, in order to minimize pixel-scale fraction errors [39-40].

\section{Sub-Pixel Level Vegetation Analysis}

MESMA has the capability the produce three different endmembers (beside another endmember for shade fraction). However, this study used MESMA to produce only two required endmebers: green vegetation (GV) and non-vegetation (Non-Veg) fractions. GV refers to all natural and cultivated vegetation, and Non-Veg refers to bare soil and built-up areas. Two spectral libraries for GV and Non-Veg were developed using VIPER tools as discussed in Halligan et al. [39] and the Viper Tools manual [40], and were utilized to develop a MESMA model for GV and Non-Veg for each Landsat7 image individually.

After excluding the shade fraction; the final result of this process was two bands of GV and Non-Veg fractions. The 'raster calculator' tool in ARCGIS was used to extract the percentage of GV inside each pixel by applying two equations:

$$
\begin{aligned}
& \mathrm{X}=\mathrm{GV}+\text { Non-Veg } \\
& \mathrm{M}=(\mathrm{GV} / \mathrm{X}) * 100
\end{aligned}
$$

...where GV is the green vegetation fraction, Non-Veg is the non-vegetation fraction, and $\mathrm{M}$ is MESMA analysis final result for each image. 
Then the results of each period were combined to produce one single image representing the highest available vegetation percentage in each pixel using the 'mosaic with the maximum value' function.

\section{Extract Vegetation Changes}

Changes in vegetation percentage between each two continuous periods were calculated for 2011 and 2012 using the 'raster calculator' tool in the ARCGIS environment as follows:

$$
\begin{aligned}
& \mathrm{VC} 1=2^{\text {nd }} \mathrm{PM}-1^{\text {st }} \mathrm{PM} \\
& \mathrm{VC} 2=3^{\text {rd }} \mathrm{PM}-2^{\text {nd }} P M
\end{aligned}
$$

...where $\mathrm{VC} 1$ and $\mathrm{VC} 2$ are vegetation change maps for 2011 and 2012, and $1^{\text {st }} \mathrm{PM}, 2^{\text {nd }} \mathrm{PM}$, and $3^{\text {rd }} \mathrm{PM}$ are first period, second period, and third period mosaics, respectively.

\section{Vegetation Loss Detection Inside Oil Spill-Impacted Areas}

Oil spill-impacted areas of each year were superimposed on their respective vegetation change maps. A buffer with 50 meters was applied for impacted areas, and then these buffers were used to clip vegetation change maps. The extracted pixels were converted to points using the 'raster to point' tool. Points that have positive values were isolated from the analysis process. Then impacted areas were visually revised individually to manually delete large blocks of points that have narrow negative values caused by the draught effect. Finally, the impacted areas that contain the remaining points are considered as impacted areas that have vegetation loss caused by an oil spill.

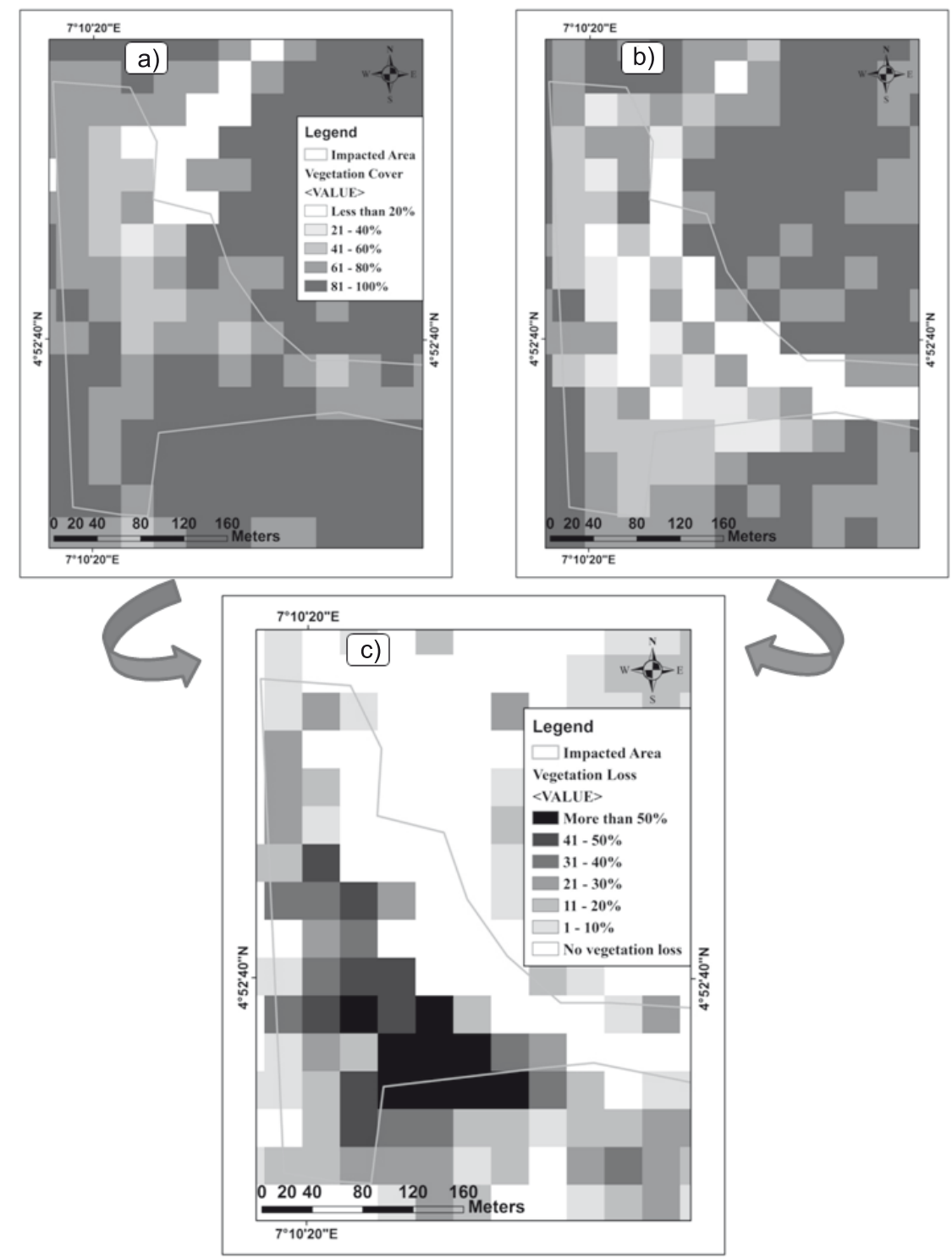

Fig. 2. 12" Imo River 1 and 2 Ogale pipeline spill on 1 November 2012. a) Second period mosaic, b) Third period mosaic, c) 2012 Vegetation loss percentage. 


\section{Examination of Oil Spill Influence Determinants on Vegetation}

Fifteen potential determinants of oil spill influence on the Delta's vegetation were examined by comparing the number of impacted areas that have vegetation loss caused by an oil spill with impacted areas that have no vegetation loss based on each potential determinant.

These fifteen potential determinants were selected according to spatial considerations (impacted area size, impacted area environment, soil type, and size of the area burnt by fire), Incident data considerations (cause of the incident, total spilled oil volume, residual oil volume on site, and spilled oil volume on open water), timing considerations (time of the incident, time of response, time of the recovery process, and time of cleanup residual impact), and oil and facilities data considerations (oil type, facility type, and pipeline size).
SPSS software was used to determine the relationship between vegetation loss results and descriptive potential determinants by using Pearson Chi-Square test, and numerical potential determinants using Spearman's correlation coefficient (Spearman's rho).

\section{Results and Discussion}

\section{Vegetation Loss Analysis Results}

This study investigated vegetation degradation inside 163 oil spill-impacted areas during 2011 and 2012 in the Rivers State. Twenty spill-impacted areas were excluded from the final result due to missing data caused by cloud cover and SLC-Off problems in Landsat7 images. Vegetation loss analysis revealed 104 impacted areas (73\%) have vegetation loss caused by oil spills. Fig. 2
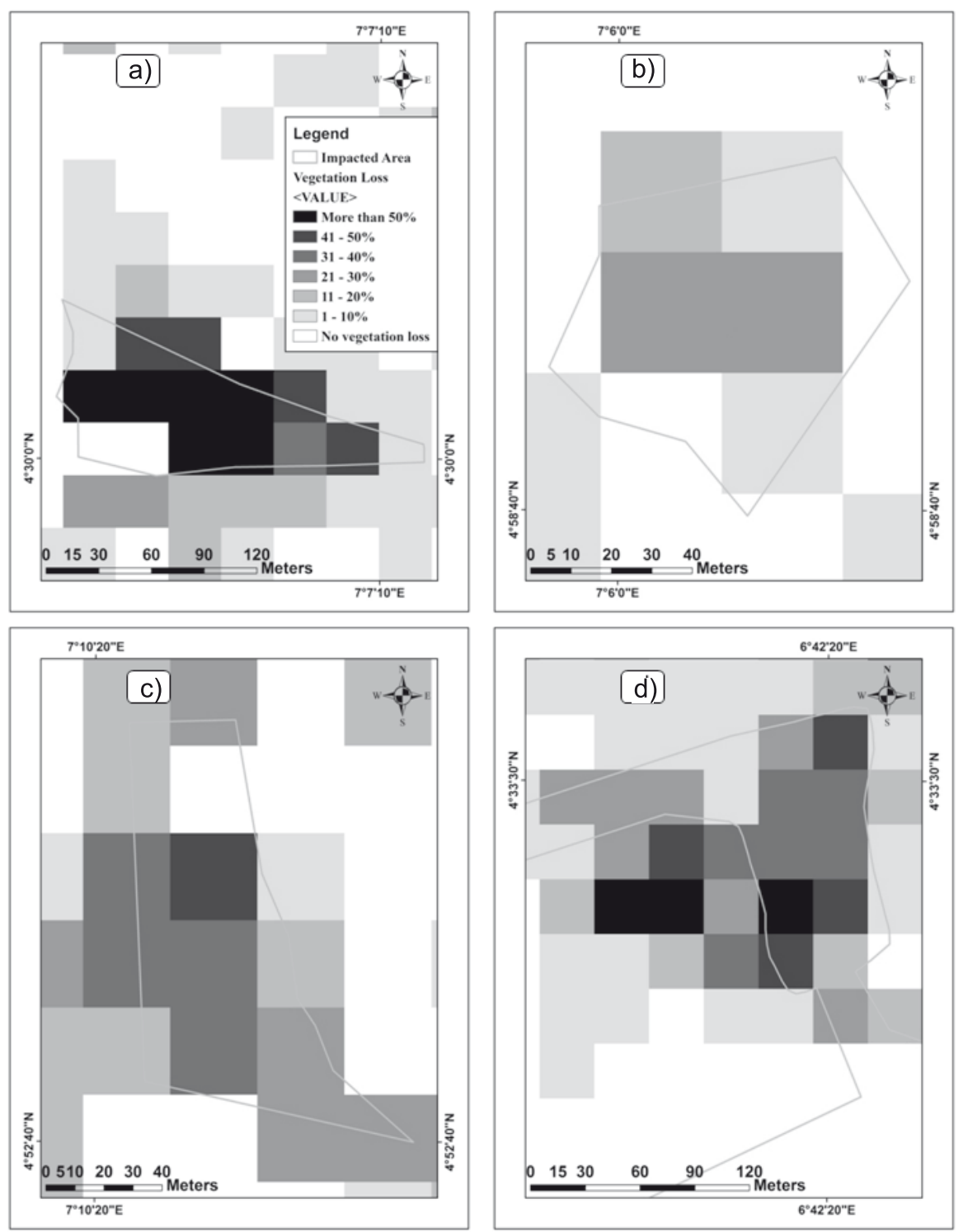

Fig. 3. Samples of vegetation degradation analysis results. a) 24" Alakiri - Bonny Pipeline in 20/06/2012, b) 4" Nkali Well 10L Flow line in 18/04/2012, c) 12" Imo River - Ogale Pipeline in 02/08/2011, d) 10" Ekulama 1 - Sanbarth Pipeline in 13/05/2012. 
represents a sample of loss analysis in the Imo River 1 and 2 Ogale pipelines caused by an oil spill incident on 1 November 2012, and Fig. 3 represents four additional samples of vegetation loss inside impacted areas.

Historical high resolution images of GoogleEarth software were checked out online to visually confirm results of the vegetation loss analysis. A comparison between images before and after the spill was conducted for this purpose. Seventy-four spill-impacted areas were investigated. The accuracy revealed from these historical images for the analysis result was $91.8 \%$.

\section{Determinants of Oil Spill Influence on Vegetation}

\section{Pearson Chi-Square Results}

Pearson Chi-Square test didn't reveal any significant differences between the variables of spill incident causes (operational or vandalism), incident time (during the rainy or dry season), spilled oil type (Bonny light or Bonny medium), the impacted area's soil type (clay, medium sand, loamy, or laterite), and oil spill source facility (oil pipeline, well head, flow station, flow line, delivery line, or manifold) in the vegetation loss results. These results may indicate that none of these factors could be considered as a determinant for oil spill influence on the Niger Delta's vegetation Table1 represents $\mathrm{P}$-value for descriptive detrminants tested by Pearson ChiSquare.

The environment of oil spill-impacted area can be considered as a determinant of oil spill influence on the Delta's vegetation. Pearson Chi-Square revealed a significant difference between environment variables (with P-Value of 0.031 ). Results revealed that $90.6 \%$ of spill-impacted areas located on open water banks have vegetation loss caused by oil spills, compared with $72 \%$ of impacted areas located in a swampy environment and $66.3 \%$ of impacted areas located in dry lands.

This result could be explained by the quick spread of spilled oil in wetlands by water, and the cleanup difficulty in these hard-to-reach areas. This result is in line with

Table 1. Pearson's Chi-Square results.

\begin{tabular}{|c|c|c|}
\hline Groups & Determinants & P-Value* \\
\hline $\begin{array}{c}\text { Spill incident } \\
\text { determinants }\end{array}$ & Cause of the incident & 0.10 \\
\cline { 2 - 3 } & Time of the incident & 0.153 \\
\hline $\begin{array}{c}\text { Impacted area } \\
\text { determinants }\end{array}$ & $\begin{array}{c}\text { Impacted area } \\
\text { Environment }\end{array}$ & 0.031 \\
\cline { 2 - 3 } & Soil type & 0.445 \\
\hline $\begin{array}{c}\text { Oil type and volume } \\
\text { determinants }\end{array}$ & Oil type & 0.132 \\
\hline $\begin{array}{c}\text { Oil facilities } \\
\text { determinants }\end{array}$ & Facility type & 0.423 \\
\hline
\end{tabular}

* Pearson Chi-Square test
Nwankwoala and Nwaogu [1], who identified available water bodies in Etche Local Government in the Rivers State as the major distributing factors of spilled oil.

\section{Spearman's Rho Results}

Egberongbe et al. [29] stated that oil spills of less than 25 barrels are considered minor incidents, spills of between 25 and 250 barrels are considered to be medium, and spills of more than 250 barrels are major incidents. This classification was used to investigate the relationship between spilled oil amount and vegetation loss inside spill-impacted areas. Results revealed that $67.1 \%$ of minor spills have vegetation loss inside their impacted areas. This percentage has increased to $74.4 \%$ in medium spills, and reached $100 \%$ in major spill-impacted areas.

Spearman's rho has represented a significant positive relationship between spilled oil volume and vegetation loss inside impacted areas as shown in Table 2. These results are supported by the fact that even if plants have different levels of sensitivity to oil spill stress, they can generally respond quickly to high amounts of oil pollution and slow if contaminated with small amounts of oil [41].

The results revealed a positive correlation between the size of the spill-impacted area and vegetation loss in the Niger Delta. $54.1 \%$ of impacted areas smaller than $300 \mathrm{~m}^{2}$ have vegetation loss. This percentage increased to $61.3 \%$ of impacted areas with size between 301-1,000 $\mathrm{m}^{2}, 78.4 \%$ of impacted areas between 1,001-6,000 $\mathrm{m}^{2}$, and reached $94.7 \%$ of impacted areas of more than $6,000 \mathrm{~m}^{2}$. These results demonstrate the importance of preventing spilled oil from spreading in large areas, which could increase the ability of spilled oil to harm vegetation.

As a result of an oil spill, some amount of spilled oil evaporates and some other amount infiltrates into the soil. The remaining amount of spilled oil covers the soil and plant roots, and is defined as the residual oil on site. Residual oil volume on site was examined as a potential determinant of oil spill influence on vegetation inside impacted areas. Spearman's rho result has represented a positive relationship between residual oil volume and vegetation loss inside impacted areas with $\mathrm{P}$-value of 0.035 (Table 2).

In their study, Emengini et al. [41] concluded that the time of the first visible oil stress symptom on vegetation depends upon plant species type and degree of stress. Their results revealed that stress symptoms were observed in grass one week after oil treatments, whereas the forsythia shrub showed stress symptoms after two weeks. The same type of experiment has been conducted by Emengini and Ugbelase [12] on Maize plants. They noted that maize plants under medium and high levels of contamination showed some symptoms of stress by the $11^{\text {th }}$ day, and they concluded that symptoms at all levels started in a smaller degree and gradually become more severe as time progresses.

We can conclude from the last two previous studies $[12,41]$ that a quick response to and fast recovery from an oil spill is essential for protecting the impacted area's 
Table 2. Spearman's rho results.

\begin{tabular}{|c|c|c|c|}
\hline Groups & Determinants & Correlation Coefficient & Sig. (2-tailed) \\
\hline \multirow{3}{*}{ Impacted area determinants } & Impacted area size & $.403^{* *}$ & 0.000 \\
\cline { 2 - 4 } & Size of the area burnt by fire & 0.408 & 0.363 \\
\hline \multirow{3}{*}{\begin{tabular}{c} 
Impacted area determinants \\
\cline { 2 - 4 }
\end{tabular}} & Total spilled oil volume & $0.300^{* *}$ & 0.000 \\
\cline { 2 - 4 } & Residual oil volume on site & $0.272^{* *}$ & 0.004 \\
\hline \multirow{2}{*}{$\begin{array}{c}\text { Response and recovery } \\
\text { timing determinants }\end{array}$} & Time of response & 0.102 & 0.627 \\
\cline { 2 - 4 } & Time of the recovery process & $.175^{*}$ & 0.036 \\
\hline Oil facilities determinants & Pipeline size & $.176^{* *}$ & 0.001 \\
\hline
\end{tabular}

*Correlation is significant at the 0.05 level (2-tailed).

**Correlation is significant at the 0.01 level (2-tailed).

vegetation from degradation. To verify this fact in our study area, response, recovery, and cleanup times for each studied spill incident were linked to vegetation loss results and analysed using Spearman's rho. Spearman's rho revealed a positive correlation between these three determinants from one side and vegetation loss inside impacted areas from the other side (Table 2). This result demonstrates the importance of quick response, recovery, and cleanup processes to protect vegetation inside impacted areas.

Furthermore, there are three special cases of data related to oil spills that were tested using Spearman's rho: areas burnt by fire (for spill incidents that include fire), spilled oil volume on open water surface (for oil spill incidents in open water locations or that have some amount of spilled oil that have reached waterways), and pipeline size (for oil spill incidents from oil pipeline facilities). None of these three special cases represent a significant influence on vegetation loss caused by oil spills in the Niger Delta.

\section{Conclusion}

The Niger Delta is the most important economic region in Nigeria. It produces the most of the country's oil and gas. However, the Delta's environment is facing several problems due to the large number of oil spill incidents every year. Millions of oil barrels have been spilled into the environment since oil production started, resulting in severe environmental pollution in the region, including vegetation, soil, creeks, air, and drinking water.

This research studied vegetation loss caused by oil spills inside impacted areas, and examined different oil spill data to establish the determinants of oil spill influence on the Niger Delta's vegetation. The study examined 143 oil spill impacted areas during 2011 and 2012 inside the Rivers State using Landsat7 ETM+ images. MESMA was applied to detect vegetation change inside impacted areas, and results revealed that 104 impacted areas (73\%) have vegetation loss caused by oil spills.
Fifteen potential determinants of oil spill influence on vegetation have been examined using Pearson's ChiSquare and Spearman's rho tests. The results reveal that impacted area size, spilled oil volume, impacted area environment, residual oil amount on sites, response timing, recovery timing, and cleanup timing are all determinants of oil spill influence on the Niger Delta's vegetation.

\section{References}

1. NWANKWOALA H.O., NWAOGU C. Utilizing the tool of gis in oil spill management-a case study of Etche LGA, Rivers State, Nigeria. Global Journal of Environmental Sciences. 8 (1), 2009.

2. KUENZER C., VAN BEIJMA S., GESSNER U., DECH S. Land surface dynamics and environmental challenges of the Niger Delta, Africa: remote sensing-based analyses spanning three decades (1986-2013). Applied Geography. 53, 354, 2009.

3. ADELANA S.O., ADEOSUN T., ADESINA A.O., OJUROYE M.O. Environmental pollution and remediation: challenges and management of oil Spillage in the Nigerian coastal areas. American Journal of Scientific and Industrial Research. 2 (6), 834, 2011.

4. OGRI O.R. A review of the Nigerian petroleum industry and the associated environmental problems. Environmentalist. 21 (1), 11, 2001.

5. TWUMASI Y.A., MEREM E.C. GIS and remote sensing applications in the assessment of change within a coastal environment in the Niger Delta Region of Nigeria. International journal of environmental research and public health. 3 (1), 98, 2006.

6. ORIMOOGUNJE O.O.I., AJIBOLA-JAMES O. Mangrove Ecosystem Recovery and Restoration from Oil Spill in the Niger Delta: The GIS Perspective. Geoinfor Geostat: An Overview S1. 5 (2), 2013.

7. OYINLOYE M.A., OLAMIJU O.I. An assessment of the physical impact of oil spillage using GIS and Remote Sensing technologies: Empirical evidence from Jesse town, Delta State, Nigeria. British Journal of Arts and Social Sciences. 12 (2), 235, 2013.

8. NNPC. 2013 Annual Statistical Bulletin Nigerian National Petroleum Corporation http://www.nnpcgroup.com/ 
Portals/0/Monthly\%20Performance/2013\%20ASB\%20 1st\%20edition.pdf (accessed January $13^{\text {th }}, \mathbf{2 0 1 4}$ ).

9. UCHEGBULAM O., AYOLABI E.A. Satellite Image Analysis using Remote Sensing Data in Parts of Western Niger Delta. Nigeria Journal of Emerging Trends in Engineering and Applied Sciences. 4 (4), 612, 2013.

10. JHA M.N., LEVY J., GAO Y. Advances in remote sensing for oil spill disaster management: state-of-the-art sensors technology for oil spill surveillance. Sensors. 8 (1), 236, 2008.

11. FINGAS M., BROWN C. Review of oil spill remote sensing. Marine pollution bulletin. 83 (1), 9, 2014.

12. EMENGINI E.J., UGBELASE V.N. Mapping the effects of Hydrocarbon spillage on plant spectral properties. International Journal of Environmental Science, Management and Engineering Research. 2 (1), 30, 2013.

13. IVANOV A.Y., ZATYAGALOVA V.V. A GIS approach to mapping oil spills in a marine environment. International Journal of Remote Sensing. 29 (21), 6297, 2008.

14. AUKETT L. The Use of Geographical Information System (GIS) In Oil Spill Preparedness and Response. In International Conference on Health, Safety and Environment in Oil and Gas Exploration and Production. Society of Petroleum Engineers, 2012.

15. BANKS S. SeaWiFS satellite monitoring of oil spill impact on primary production in the Galapagos Marine Reserve. Marine pollution bulletin. 47 (7), 325, 2003.

16. TERUHISA K., MASAHIRO N., HIROSHI K., TOMOKO Y., KOUICHI O., Marine Life Research Group of Takeno. Impacts of the Nakhodka heavy-oil spill on an intertidal ecosystem: an approach to impact evaluation using geographical information system. Marine pollution bulletin. 47 (1), 99, 2003.

17. ROBERTS D.A., BELAND M., KOKALY R.F., COUVILLION B., USTIN S., PETERSON S. Mapping wetland species and the impact of oil from the Deep Horizon using the Airborne/Visible Imaging Spectrometer and Multiple Endmember Spectral Mixture Analysis. In AGU Fall Meeting Abstracts. 1, 2011.

18. MISHRA D.R., CHO H.J., GHOSH S., FOX A., DOWNS C., MERANI P.B., KIRUI P., JACKSON N., MISHRA S. Postspill state of the marsh: Remote estimation of the ecological impact of the Gulf of Mexico oil spill on Louisiana salt marshes. Remote Sensing of Environment. 118, 176, 2012.

19. ARSLAN M.D., FILIPPI A.M., GUNERALP I. Oil Spill Detection along the Gulf of Mexico Coastline based on Airborne Imaging Spectrometer Data. In AGU Fall Meeting Abstracts. 1, 1403, 2013.

20. KOKALY R.F., COUVILLION B.R., HOLLOWAY J.M., ROBERTS D.A., USTIN S.L., PETERSON S.H., KHANNA S., PIAZZA S.C. Spectroscopic remote sensing of the distribution and persistence of oil from the Deepwater Horizon spill in Barataria Bay marshes. Remote Sensing of Environment. 129, 210, 2013.

21. PETERSON S.H., ROBERTS D.A., BELAND M., KOKALY R.F., USTIN S.L. Oil detection in the coastal marshes of Louisiana using MESMA applied to band subsets of AVIRIS data. Remote Sensing of Environment. 159, 222, 2015.

22. SAIF UD DIN, AL DOUSARI A., LITERATHY P. Evidence of hydrocarbon contamination from the Burgan oil field, Kuwait - Interpretations from thermal remote sensing data. Journal of environmental management. 86 (4), 605, 2008.

23. HESE S., SCHMULLIUS C. High spatial resolution image object classification for terrestrial oil spill contamination mapping in West Siberia. International journal of applied earth observation and geoinformation. 11 (2), 130, 2009.

24. ANIFOWOSE B., LAWLER D.M., VAN DER HORST D., CHAPMAN L. Attacks on oil transport pipelines in Nigeria: A quantitative exploration and possible explanation of observed patterns. Applied Geography. 32 (2), 636, 2012.

25. ADAMU B., TANSEY K., BRADSHAW M.J. Investigating vegetation spectral reflectance for detecting hydrocarbon pipeline leaks from multispectral data. In SPIE Remote Sensing. International Society for Optics and Photonics, 889216, 2013.

26. ANIFOWOSE B., LAWLER D., HORST D., CHAPMAN L. Evaluating interdiction of oil pipelines at river crossings using Environmental Impact Assessments. Area. 46 (1),4, 2014.

27. FRN. Niger Delta Regional Development Master plan, Federal Republic of Nigeria, http://www.nddc.gov.ng/ NDRMP\%20Chapter\%201.pdf (Accessed March 12 ${ }^{\text {th }}$ 2015).

28. IBEANU O. Oiling the friction: Environmental conflict management in the Niger Delta, Nigeria. Environmental change and security project report. 6, 19, 2000

29. EGBERONGBE F.O., NWILO P.C., BADEJO O.T. Oil spill disaster monitoring along Nigerian Coastline. In $5^{\text {th }}$ FIG Regional Conference, Accra, Ghana. 8, March 2006.

30. KURUK P. Customary water laws and practices: Nigeria, http://weavingaweb.org/ pdfdocuments/LN190805_Nigeria. pdf. 2004 (accessed August 1 1 ${ }^{\text {st }}, 2013$ ).

31. FABIYI O.O. Change actors' analysis and vegetation loss from remote sensing data in parts of the Niger Delta region. Journal of Ecology and the Natural Environment. 3 (12), 381, 2011

32. EJIBUNU H.T. Oil Resources and Violence in Rivers State of Nigeria: Implications and the Way Forward. Being a Thesis submitted to the European University Center for Peace Studies, Stadtschlaining/Burg, Austria, in partial fulfillment of the requirements for the award of Master of Arts Degree in Peace and Conflict Studies. 2008.

33. SHELL. Oil Spills monthly reports for 2011 and 2012, Shell Petroleum Development Company (SPDC), http://www. shell.com.ng/environment-society/environment-tpkg/oilspills/monthly-data.html (accessed May $7^{\text {th }}, 2013$ ).

34. USGS. Earthexplorer United States Geological Survey (USGS) http://www.earthexplorer. usgs.gov (accessed May $25^{\text {th }}, \mathbf{2 0 1 3}$ ).

35. MAXWELL S.K., SCHMIDT G.L., STOREY J.C. A multiscale segmentation approach to filling gaps in Landsat ETM+ SLC - off images.International Journal of Remote Sensing. 28 (23), 5339, 2007.

36. NASA. The Landsat 7 Handbook, National Aeronautics and Space Administration (NASA), http://landsathandbook.gsfc. nasa.gov (accessed August $1^{\text {st }}, \mathbf{2 0 1 3}$ ).

37. USGS. Landsat Enhanced Thematic Mapper Plus (ETM+), https://lta.cr.usgs.gov/LETMP (accessed August $15^{\text {th }}$, 2014).

38. EESA, LANDSAT 8 OLI-TIRS. https://earth.esa.int/web/ guest/data-access/latest-data-products/-/article/landsat-olitirs-european-coverage, (accessed: September $1^{\text {st }}, \mathbf{2 0 1 4}$ ).

39. HALLIGAN K., ROBERTS D., DENNISON P. VIPER Tools user manual." Univ. of Calif., Santa Barbara, California. http://www.scribd.com/doc/141164870/VIPER-Tools-UserManual-v1-5\#scribd. 2007 (accessed August $1^{\text {st }}$, 2013).

40. VIPER Tools. http://www.vipertools.org/?q=content/mesma (accessed May $15^{\text {th }}, \mathbf{2 0 1 3}$ ).

41. EMENGINI E.J., EZEH F.C. CHIGBU N. Comparative Analysis of Spectral Responses of Varied Plant Species to Oil Stress. International Journal of Scientific \& Engineering Research. 4 (6), 2013. 